\title{
Las brumas de duda histórica y geográfica: El indio desconocido, la Casa de Derechos Humanos de Punta Arenas y la interpretación del patrimonio cultural
}

The mists of doubt in history and geography: The Unknown Indian, the House of Human Rights of Punta Arenas and the interpretation of cultural heritage

\author{
IAIN DAVIDSON ${ }^{\mathrm{a}}$

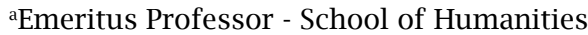 \\ University of New England, Australia \\ $\bowtie$ Iain.Davidson@live.com.au
}

"the foggy ruins of time"

Bob Dylan, Mr. Tambourine Man

\section{RESUMEN}

El artículo analiza la política del patrimonio cultural mediante algunas ideas sobre las relaciones entre los productores del patrimonio y su cultura, y entre los consumidores del patrimonio y la suya. Es necesario diferenciar entre los herederos de una cultura -primeros habitantes de un país- junto con lo que representa el patrimonio para ellos, y los forasteros -colonos o turistas- con respecto a la misma cultura y patrimonio. Finalmente, se hace una distinción entre dos tipos de materialidad que tienen importancia patrimonial: P1) las construidas con motivo de crear patrimonio (como estatuas); y P2) cosas construidas por casualidad (como restos de edificios históricos). Estas ideas se desarrollan aquí observando los intereses de distintos grupos relacionados con el "Indio Desconocido", y la Casa de Los Derechos Humanos de Punta Arenas, donde es deseable que se desarrollen interpretaciones de los sitios para distinguir los intereses de los distintos grupos.

PALABRAS CLAVE: patrimonio cultural, cultura, indio desconocido, Casa de Derechos Humanos, Punta Arenas.

ABSTRACT

Cultural heritage policy is discussed here through some ideas on the relationship between heritage producers and their culture, and between heritage consumers and theirs. 
It is necessary to differentiate between the heirs of a culture - the first inhabitants of a country - together with what heritage represents for them, and the outsiders - settlers or tourists - with respect to the same culture and heritage. Finally, a distinction is made between two types of materiality that have heritage significance: P1) those built for the purpose of creating heritage (such as statues); and P2) things built by chance (such as remains of historical buildings). These ideas are developed here by observing the interests of different groups related to the "Unknown Indian" and the House of Human Rights in Punta Arenas, where it is desirable to develop interpretations of the sites to distinguish the interests of different groups.

KEY WORDS: cultural heritage, culture, indio desconocido, casa de derechos humanos, Punta Arenas.

\section{INTRODUCCIÓN}

En un contexto en que el $45^{\circ}$ Presidente de los Estados Unidos diera la impresión de querer destruir todo tipo de protección del patrimonio cultural y ambiental en su país ${ }^{1}$, conviene entender y profundizar respecto del proceso político de estas protecciones. Destruir la protección tiene las mismas consecuencias que destruir el patrimonio, de la manera que se ha visto durante los últimos tiempos en el Medio Oriente². En todos los países, la conservación del medio ambiente y del patrimonio cultural dependen de la voluntad del pueblo y de la legislación nacional, y en estos dos sentidos, la determinación de proteger el patrimonio es siempre una decisión política. Este artículo trata sobre algunos problemas de esta política, ya sea en el ámbito de los partidos políticos, de los conflictos de intereses entre las empresas privadas y los defensores de la conservación, o bien, en las decisiones personales. Por ello, sostenemos que la protección de todo tipo de patrimonio necesita ser defendida en todo momento, frente a la dificultad de definir sus beneficios (o, al parecer, a pesar de sus beneficios). La única forma de defensa en este ámbito es mediante la educación del público, incorporando la interpretación de los sitios de patrimonio, que en este caso, se refieren al patrimonio cultural.

Todas las reivindicaciones del Patrimonio son actos políticos, incluyendo aquellos casos en que la apariencia nos hace suponer que no estamos en presencia de algo relativo al patrimonio.

1 Departamento del Interior de los Estados Unidos (5 de mayo de 2017). Esta entidad gubernamental publica la lista de monumentos bajo revisión, anuncia el primer período formal de comentarios públicos para monumentos de la Ley de Monumentos de Antigüedades (U.S. Departament of the Interior. Department Releases List of Monuments Under Review, Announces First-Ever Formal Public Comment Period for Antiquities Act Monuments). URL: https://www.doi.gov/pressreleases/interior-department-releases-list-monuments-under-review-announces-first-ever-formal

2 The Conversation (4 de junio de 2017) 'Borrando la historia: por qué el Estado islámico está destruyendo con explosiones artefactos antiguos’ (Erasing history: why Islamic State is blowing up ancient artefacts). URL: https:// theconversation.com/erasing-history-why-islamic-state-is-blowing-up-ancient-artefacts-78667 
Esto se puede ver en las frases comunes empleadas por las diferentes agencias del Patrimonio Gubernamental (ver por ejemplo sobre la protección chilena a González Carvajal, 2004) que hablan de "aspectos de nuestro pasado que nosotros queremos mantener... y pasar a las generaciones futuras". La naturaleza política de esto se identifica al considerar quiénes somos cuando se hace referencia a "nosotros" y por qué "queremos mantener" cualquier cosa ¿Cuáles son las partes interesadas y cuál es su motivación? ¿Qué clase de cosas son las que "queremos mantener"?

Además, el patrimonio se crea. Se crea en un nivel muy fundamental en forma de cosas materiales -obras de arte, edificios, monumentos y sitios modificados- producidos por las personas en las sociedades. También se concibe por medio de las creaciones intangibles, como los productos culturales transmitidos oralmente, y muchas veces las historias y los cuentos que dan sentido a estas cosas materiales. También se crea en el sentido de dar importancia patrimonial a algo. Es cierto que cualquier cosa material tiene (o no) valores estéticos derivados de los valores actuales, incluso debido al mercado ilegal de bienes arqueológicos (Rivera, 2012). Pero también las cosas tienen valores derivados de su pasado siempre que se cuentan historias -patrimonio intangible- sobre ese pasado.

Incluso en el caso de los lugares naturales que se consideran de importancia patrimonial, la naturalidad de los paisajes es una apariencia o interpretación. Su carácter creado se manifiesta de dos maneras: en primer lugar, la mayoría de los paisajes que han sido habitados continuamente por personas en cualquier tiempo no es, de ninguna manera, "natural", sino que lleva las marcas en mayor o menor medida de ese largo uso del paisaje; en segundo lugar, la selectividad implicada en la consideración que tuvieron algunos habitantes, y no otros, de estos paisajes son dignos de la protección como ejemplos del patrimonio, implicando la creación de un conjunto de valores que dan preferencia a un paisaje más que al otro. Igual que las consideraciones de patrimonio cultural, hay dos maneras de ver el medio ambiente, una que tiene en cuenta su historia de transformaciones por parte de la gente, y otra, que lo considera de una manera digamos más romántica, como nada más que una cosa de belleza.

Finalmente, en términos de los criterios más fundamentales, no existe nada fijo sobre el patrimonio. El hecho mismo de que en distintos momentos las creaciones que son diferentes a las convencionales se consideren dignas de protección, o que algunos lugares finalmente logren reconocimiento después de muchos rechazos demuestra que es así. Incluso es probable que en algún momento los lugares puedan perder su estatus de patrimonio ${ }^{3}$.

\section{¿Qué es el patrimonio cultural?}

Lo importante es entender qué es el patrimonio cultural (ver Harrison, 2010). Esto está

\footnotetext{
Esto también puede ocurrir sin la participación de aquellos grupos que pueden tener interés en un monumento. Ejemplo de esto fue la reciente destrucción -por decisión del gobierno turco- del memorial dedicado a los soldados australianos fallecidos en la invasión británica de 1915 en Anzac Cove, península de Gallipoli, Turquía. Ver: NZ Herald (17 de junio de 2017) Gobierno turco destruye monumento Anzac (Turkish Government destroys Anzac monument) URL: http://www.nzherald.co.nz/nz/news/article.cfm?c_id=1\&objectid=11878350
} 
consagrado en la Convención del Patrimonio Mundial de la UNESCO ${ }^{4}$ donde se reconocen tres categorías de patrimonio cultural: monumentos; grupos de edificios; y sitios. En cada una de estas categorías, los elementos pueden considerarse si son de "valor universal sobresaliente" desde el punto de vista de "historia, arte o ciencia" para las dos primeras categorías, o desde "el punto de vista histórico, estético, etnológico o antropológico" para la tercera categoría. El Patrimonio Mundial no es el único contexto para la gestión del patrimonio cultural, y es importante reconocer que el patrimonio cultural y los paisajes culturales van más allá de los "valores universales sobresalientes". Esto se debe a que tales objetos, lugares y paisajes sólo alcanzarían un valor universal si su importancia se reconoce también entre las comunidades locales. El patrimonio cultural está constituido por aquellos lugares y cosas, junto con las historias según sostiene $\mathrm{Hu}(2017)^{5}$ y signos intangibles de los valores que definen la manera en que llegamos a ser las sociedades que somos. En consecuencia, es necesario reconocer que los cuentos e historias tienen valor patrimonial aunque no hay cultura material relacionada con ellos. Esto se llama patrimonio intangible, aunque Harrison (2010) prefiere hablar de "prácticas de patrimonio", incluyendo las lenguas usadas en la comunicación cotidiana y para contar historias, es decir, los mismos cuentos e historias, más los rituales, la música, y las danzas.

En realidad, existe una relación estrecha entre estas características que se llaman "patrimonio material e intangible" y la cultura, en el sentido antropológico (Bennett, 2005; Davidson, 2016; Kuper, 1999). Una de las primeras definiciones de "cultura" en el sentido antropológico fue la de Tylor (1871) y decía lo siguiente:

"La cultura o civilización, en su amplio sentido etnográfico, es ese conjunto complejo que incluye el conocimiento, la creencia, el arte, la moral, el derecho, la costumbre y otras capacidades y hábitos adquiridos por el hombre como miembro de la sociedad" (Tylor, 1871, p. 1).

Esta definición (con el uso cultural de su época de la palabra "hombre" de una manera que debe incluir a las mujeres también), estableció como se puede entender el concepto de la cultura en los últimos años del siglo XIX, durante los cuales se vieron los comienzos del estudio sistemático de otros pueblos por las ciencias sociales (entre ellas, la Antropología). Las palabras de Tylor (1871) se refieren solamente al patrimonio intangible pero tienen implicaciones para la cultura material. Hay dos consecuencias de esta relación entre la cultura y el patrimonio: 1) la naturaleza de las cosas materiales o inmateriales del patrimonio

4 United Nations Educational, Scientific and Cultural Organization, UNESCO (Organización de las Naciones Unidas para la Educación, la Ciencia y la Cultura) (1972) Convención sobre la protección del patrimonio mundial, cultural y natural. URL: http://whc.unesco.org/en/conventiontext

5 Hu, D. (16 de mayo de 2017) The revolutionary power of Andean folk tales (El poder revolucionario de los cuentos populares andinos). En Sapiens. URL: https://www.sapiens.org/archaeology/andean-folk-tales-revolutionarypower/ 
está determinada por la cultura de las personas que viven, o vivieron una vez, entre esos monumentos, edificios o sitios; 2) para muchos de nosotros, arqueólogos o turistas, las partes, los fragmentos, vienen a simbolizar toda la cultura, y queremos imaginar o tal vez reconstruir, a base de los restos materiales, las historias, los rituales, la música y las danzas a pesar de que las personas han desaparecido.

El patrimonio, pues, tiene aspectos inmateriales, y a veces materiales. Es decir, todo patrimonio tiene o tenía un aspecto inmaterial. Pueden existir canciones, cuentos e historias sin aspecto material, no obstante el patrimonio material siempre tiene, o tenía un aspecto inmaterial, ya que habían historias o relatos relacionados con ello. Los dos aspectos forman una parte fundamental de la cultura de los productores responsables del patrimonio. En este sentido, el patrimonio pertenece al presente y es difícil de distinguir de la cultura, ya que es una parte de ella, en el sentido de que la manera de dar cuenta del pasado, es una parte de la cultura. Pero llega un momento en que estas características de la cultura pertenecen al pasado y llegan a considerarse "patrimonio" (ver Fig. 1).

Fig. 1. Producción y consumo del Patrimonio y la cultura.

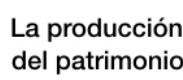

del patrimonio
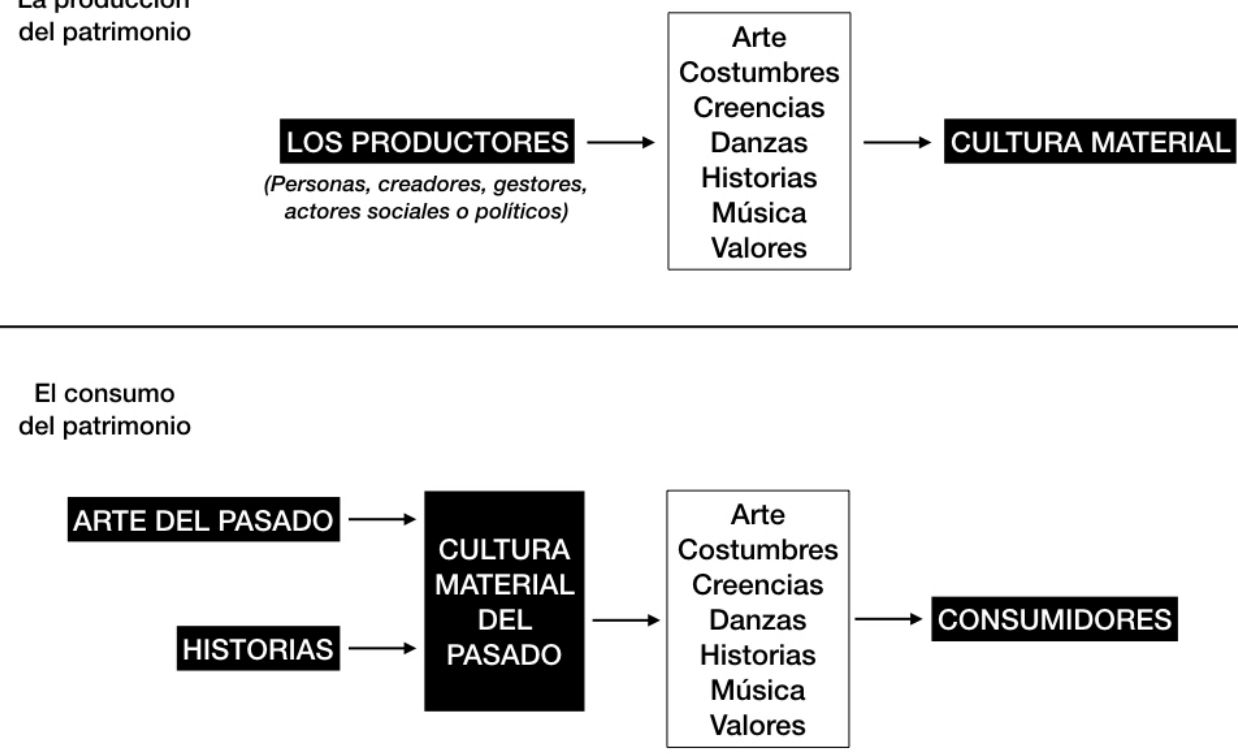

Fuente: Elaboración propia.

Para la mayor parte del patrimonio, lo que queda de la cultura del pasado es de su cultura material -estos "monumentos; grupos de edificios, y, sitios" definidos por el Patrimonio Mundial ${ }^{6}$, incluyendo algo restante del arte de la época. También existen algunas historias que se han transmitido desde el pasado, a veces porque sirven a un

6 UNESCO (1972) Convención sobre la protección del patrimonio mundial, cultural y natural. URL: http://whc. unesco.org/en/conventiontext UNESCO (1972) Convención sobre la protección del patrimonio mundial, cultural y natural. URL: http://whc.unesco.org/en/conventiontext 
propósito en el presente. Luego, hay dos clases de consumidores: Los Herederos, las personas que tienen una relación histórica con los productores del patrimonio; y Los Forasteros, las personas que no tienen esa relación, gente como, por ejemplo, los turistas. En el momento de ver (o consumir) este patrimonio las dos clases de consumidores están influenciados por las características de su propia cultura. Para Los Herederos, los conocimientos sobre el patrimonio de su pueblo llegan a ser parte de su propia cultura. Para Los Forasteros, el patrimonio de otros influye en su cultura (como cualquier otra experiencia), pero de una manera más superficial. Es importante reconocer que los Forasteros aportan valor a la cultura material de "otros" de una forma que está mediatizada por sus propias experiencias de lo que tiene valor. A modo de ejemplo, parte de las razones por las que Occidente ha estado tan consternado por la destrucción de la antigua ciudad de Palmyra, en Siria, por parte de ISIS ${ }^{7}$ (ver Zorich, 2016), es que las ruinas son de un tipo bien conocido y valorado para la gente occidental. En este sentido, y desde una perspectiva neo-colonialista, las columnas y calles de la ciudad son consideradas como preocupaciones de Herederos de aquel Patrimonio, y no de Forasteros.

El novelista inglés L.P. Hartley (1953) escribió: "El pasado es un país extranjero; Hacen las cosas de manera diferente allí”. Lo curioso es que somos todos de afuera (Davidson, 2011). En el caso de Los Herederos, el otro país es su propio pasado, nada más; el de Los Forasteros es el pasado del otro grupo junto con la "alteridad/otherness" de la cultura distinta. El consumo del patrimonio obliga a todos a apreciar cómo las personas del "otro país" hacían las cosas de manera diferente, visto a través de la lente de nuestra propia cultura. El gran reto que plantea la valorización del patrimonio cultural es cómo comprenderlo, a pesar de que somos culturalmente diferentes de las personas que lo crearon, y a pesar de que lo que apreciamos es sólo una pequeña fracción del contexto cultural de su producción. Todo depende de nuestra cultura de hoy, junto con ubicar las diferencias entre Los Herederos y Los Forasteros.

El patrimonio cultural está lleno de tales contrastes (Davidson, 2008), empezando con el ya mencionado contraste entre las cosas del patrimonio material y los conocimientos del patrimonio inmaterial. Además, hay varios contrastes que surgen de la naturaleza de la audiencia o de los consumidores del patrimonio. Sobre todo hay diferencia entre lo que se puede considerar personal o informal por una parte, y lo que es digno de protección debido a su importancia para muchas más personas. En efecto, es importante reconocer un contraste importante entre las cosas o costumbres que tienen importancia patrimonial: P1) las construidas con motivo de crear patrimonio, o P2) las construidos por casualidad debido a las historias o cuentos relacionados con ellos. Lo cual quiere decir que el sentido del patrimonio resulta de una relación entre uno o varios individuos y el sitio o material patrimonial. El patrimonio, y -sobre todo- la importancia del patrimonio, no es una calidad ni esencia inherente de un lugar o cosa, sino que se refiere a las relaciones personales con el lugar o cosas que le dan importancia.

Estado Islámico ISIS, grupo radical islamista. 


\section{¿Quién tiene intereses con respecto al patrimonio?}

De acuerdo a las definiciones ya expuestas, podemos decir que los intereses que una persona puede tener en el patrimonio dependen de la historia personal de cada uno: a) su educación, por ejemplo con respecto a lo que son las cosas bellas o importantes; b) su situación de clase y privilegio; c) la importancia de las historias y cuentos de la vida, las personales, las regionales y las nacionales, incluso su conocimiento de las historias relacionadas con el patrimonio; y d) sus relaciones con el mundo comercial. Vale decir, dónde, cuándo y cómo una persona obtiene sus valores es lo que define para ésta lo que es o no es importante. Esto se refiere a que los intereses de cada individuo que corresponda al grupo de los Herederos, dependen de su ubicación dentro de la cultura de su sociedad. En el fondo, lo que constituye el Patrimonio es un asunto personal, depende de la importancia que un individuo le da a la historia y al medio ambiente de la cultura material. Por otra parte, los intereses de los Forasteros en el Patrimonio de otro país, dependen de los valores que los individuos han adquirido a través de su propia cultura, considerando que muchas veces estos valores no son del todo compatibles con los de los Herederos.

\section{El Indio Desconocido como ejemplo de la transformación} de un tipo de patrimonio: (P1) al otro (P2)

Merece la pena usar las categorías de P1 y P2 (ver p.9) para analizar la tumba del Indio Desconocido en el Cementerio Municipal Sara Braun de Punta Arenas. Se trata de una tumba y un monumento en el cementerio en forma de una estatua modelada en bronce inspirada en la foto de un fueguino (Fig. 2) ${ }^{8}$. Delante hay una placa de bronce con unas líneas de epitafio escritas por el poeta de Punta Arenas, José Grimaldi Acotto: "El indio desconocido llegó desde las brumas de la duda histórica y geográfica. Y yace aquí cobijado en el patrio amor de la chilenidad". Estas son las brumas de la duda que se plantean en el título de este artículo, cuyo objetivo trata de cómo el patrimonio se relaciona con otro concepto: "chilenidad." Como decía Rivera (2012) las cosas patrimoniales "representan una realidad que nos conecta y traslada del pasado al presente, influenciando nuestras vidas, es decir, constituye una fuente de nuestra propia identidad" (Rivera, 2012, p. 157).

La historia de cómo el aborigen llegó a estar en el cementerio es curiosa y demuestra que los responsables empezaron con la intención de construir un monumento de tipo P1. Observamos desde el principio que el concepto de "Heredero" es inadecuado, puesto que el monumento es una creación de los colonos y no de la sociedad del nativo.

Dentro de la tumba están las osamentas de dos individuos, las del aborigen y las de

\footnotetext{
8 Para más detalles respecto de episodio, véase: Plath, O. (1993) L’Animita: Hagiografía Folklórica, pp: $204-208$.
} 


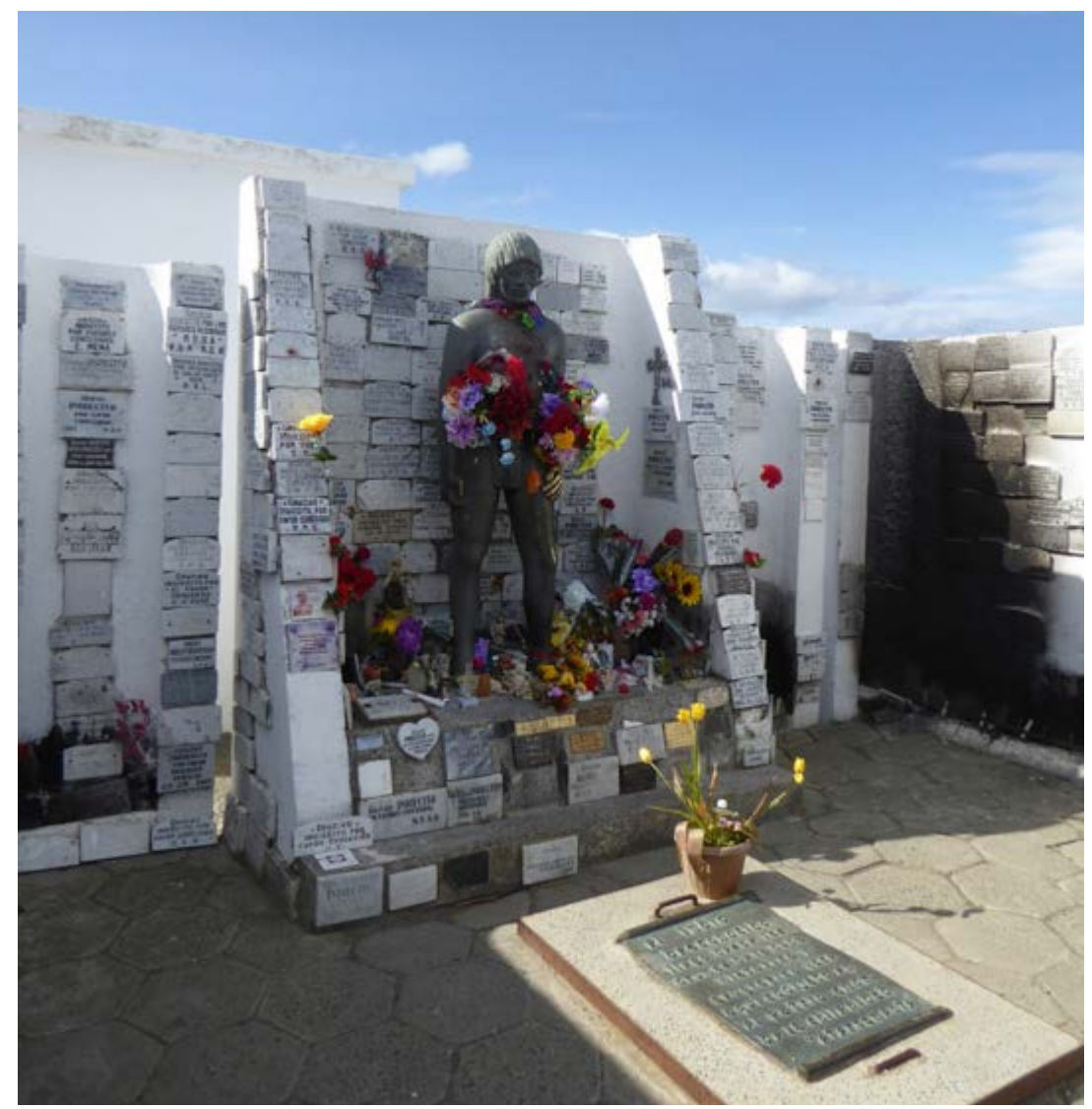

Fig. 2. La tumba del Indio Desconocido, Cementerio Municipal Sara Braun de Punta Arenas (Foto Iain Davidson).

un habitante de la isla de Chiloé llamado David Leal. Los cuerpos se encontraron en la isla Diego de Almagro $^{9}$ en el año 1929, durante los primeros días de explotación de una cantera de mármol. Las brumas de duda esconden toda la historia de interacción entre los aborígenes -probablemente canoeros de la isla ${ }^{10}$ y los dos empleados de la entonces recientemente creada Compañía de Mármoles Cambridge, siendo uno de ellos, el aludido David Leal. Lo cierto es que lo único que se sabe de lo que aconteció, estaba dicho y escrito por individuos ajenos a los canoeros, ergo, es probable que el indio haya sido desconocido para los noindígenas, David Leal y su compañero, pero no para su pueblo. Por lo tanto, el santuario es un monumento de tipo P1, vale decir, producido por los habitantes no-indios y asociado a gente ajena a ellos.

9 Localizada en pleno archipiélago patagónico, específicamente a $51^{\circ} 30^{\prime}$ ' S - $75^{\circ} 15^{\prime}$ O, anteriormente era denominada 'Cambridge', el actual nombre de la isla celebra el conquistador Diego de Almagro quien fue el primer español en reclamar la posesión de Chile, en nombre del rey español, Carlos (Risopatrón, 1924: 124; Subercaseaux, 2005, p. 266).

10 Y de hecho parece que la estatua esta modelada sobre la imagen de un indio canoero (Jordi Estévez, comunicación personal, 4 de Junio de 2017). 
En base al esquema "Producción y consumo del Patrimonio y la cultura" (fig. 1, p. 7), en este caso, los habitantes no indígenas de Punta Arenas fueron los productores del monumento patrimonial, un monumento filtrado a través de sus valores culturales, particularmente sus costumbres de entierro y sus actitudes culturales hacia los nativos. Refleja también la inserción de los productores dentro del sistema económico, quienes valoraban el mármol de la cantera de la isla Diego de Almagro, llamada así por un héroe de la sociedad colonial (“Settler society") de Chile. Es un producto de la sociedad de la chilenidad, incluyendo la prospección de mármoles por parte de los colonos ("settlers"), y el reconocimiento de sus relaciones de alteridad con los indios. En este sentido, los indios cuyos restos y representaciones se conmemoran, son en realidad forasteros en la producción de su patrimonio.

Al mismo tiempo, dentro la misma sociedad chilena hay otro grupo de forasteros con respecto al patrimonio de tipo P1. Se trata de los habitantes de Punta Arenas, quienes tratan al indio como algún tipo de figura religiosa capaz de intervenir con respecto a sus problemas personales. Esta conducta no tiene nada que ver con la indigeneidad del indio, ya que más bien responde a los valores culturales de memorialización de una parte de la sociedad colonial. Derivadas de aquella concepción, surgió la idea de dejar velas, dinero y -una vez que se pensó que llegaba la ayuda encomendada- placas de agradecimientos. En consecuencia, la estatua está rodeada por muros atiborrados de placas de agradecimiento.

En consonancia con este análisis, se puede establecer que los suplicantes son forasteros con respeto al indio, y lo demuestran usando el diminutivo condescendiente "indiecito". Todo el aparato de velas, ofrendas monetarias, flores y placas de agradecimiento, deriva de una tradición cultural completamente ajena a cualquier cultura del aborigen o del conocimiento de la cultura canoera. Por casualidad, la incorporación del indio dentro de la cultura de la sociedad colonial de Chile, ha hecho que el monumento patrimonial del tipo P1, haya pasado a transformarse en uno de tipo P2.

Observando este ejemplo, vemos que hay intereses de varias personas: del aborigen canoero austral; del desventurado David Leal; de aquellos con interés por la explotación de mármoles; de los iniciadores, las personas que construyeron la tumba y encargaron la estatua; de los suplicantes que valoran el sitio como un santuario; y de los verdaderos forasteros, los turistas.

Los restos mortales del indio podrían haber quedado depositados o dispuestos en su territorio ancestral, vale decir, en alguna de las islas del archipiélago patagónico, pero ni él ni los otros miembros de su pueblo aborigen tuvieron el poder de elegir. Ni siquiera un eventual traslado podría proteger esos intereses pasados. De igual modo, no se tuvo en cuenta la voluntad de David Leal, quien está enterrado en la tumba con el indio, pero aún así todo el mundo la considera como la tumba del "Indio Desconocido", pese a que se podría hablar también del "David Leal Desconocido".

Los intereses de los "marmoleros" parecen haber sido satisfechos quitando los inconvenientes de la presencia de los nativos. Los intereses de los iniciadores y los suplicantes 


\section{DAVIDSON}

aparentemente también fueron cumplidos, aunque es posible imaginar que pudo generarse un conflicto entre los que querían hacer una declaración sobre el pueblo indígena, y aquellos que adoptaron a este individuo con sus propios fines religiosos. De una manera $u$ otra, había política en cada afirmación explícita o implícita de los derechos. Y cualquiera que sea la intención original de establecer la tumba, la incorporación de la manifestación material dentro de la cultura local, hizo casi inevitable que la naturaleza del estatus patrimonial pudiera ser o fuera transformada y se convirtiera en un rasgo de la cultura local, muy alejado de los intereses del infortunado habitante inmemorial de los canales patagónicos.

\section{La Casa de Derechos Humanos como ejemplo de la transformación de un tipo de patrimonio (P2) al otro (P1)}

La transformación del otro tipo (P2 a P1) tiene lugar con edificios antiguos o ruinas ${ }^{11}$. El proceso, cuando algunos de estos espacio llegan a ser de importancia para la conservación patrimonial, es completamente un producto del azar, considerando aspectos como: la naturaleza de la construcción original, el cuidado con el que se le trató en el pasado y el daño que sufrió por desgaste natural, o bien, destrucción incidental o deliberada. Comienzan como sitios patrimoniales de tipo P2 (construidos por casualidad), en el sentido de que fueron edificios cotidianos y se transforman en algo del tipo P1 (construidos con motivo de crear patrimonio), por el proceso de protección y conservación de su materia física.

Un ejemplo en Punta Arenas es la Casa de los Derechos Humanos, ubicada en Avenida Colón 636, (Figura 3), que fue antes el centro de detención y tortura entre 1973-1990², llamado por los torturadores -con un claro sentido de humor negro- como el "Palacio de las Sonrisas." Actualmente, este edificio está dedicado a la conmemoración de la crueldad de los años de la dictadura, de una manera parecida a la que ocurre en otros países que han sufrido torturas ${ }^{13}$. Fue declarado Monumento Histórico y Nacional siendo concebido como un Monumento Histórico y Nacional ${ }^{14}$, concebido "como registro de las violaciones a los derechos humanos cometidas en la región” ${ }^{15}$. Complementariamente, al frente del edificio se erigió un

11 Con respecto a un caso del patrimonio de China, específicamente la destrucción del Palacio de Verano en Beijing en 1860 por tropas británicas. Entre las edificaciones dañadas que han sido restauradas hoy figura el Corredor Largo de 728 metros de largo. Davidson, I. (14 de octubre de 2015) Patrimonio, el barco de Teseo y la canción de Homero. En Envirosociety (Heritage, the ship of Theseus and the song of Homer). URL: http://www.envirosociety.org/2015/10/

12 De la Jara Sotomayor, P. (16 de septiembre de 2014) El Magallanews. Punta Arenas: “Agrupación de DD.HH. organizó un recorrido por ex centros de detención y tortura”. URL: http://www.elmagallanews.cl/noticia/sociedad/puntaarenas-agrupacion-de-ddhh-organizo-un-recorrido-por-ex-centros-de-detencion-y

13 Ver, por ejemplo, el caso de los húngaros. En Budapest, capital de Hungría, abrió sus puertas en 2002 el Museo La Casa del Terror (House of Terror Museum), con exhibiciones dedicadas a los regímenes fascistas y comunistas que tuvo dicho país durante el S. XX, además de ser un memorial para las personas que fueron detenidas, interrogadas, torturadas y asesinadas en dicho edificio durante los mencionados regímenes. URL: http://www.budapest.com/ city_guide/culture/museums/house_of_terror_museum.en.html?sid=pnsica10kiugmd6mkh8dtmdfj1consultado 15-junio-2017

14 Decreto Nº95 de 2016 que declara Monumento Nacional en la categoría de Monumento Histórico a la Casa de Los Derechos Humanos - Residencia Beaulier, ubicada en la comuna de Punta Arenas, Provincia de Magallanes, Región de Magallanes y Antártica Chilena. URL: http://monumentos.cl/sites/default/files/decretos/MH_01513_2016_D00095.PDF 
monumento, en cuyas placas conmemorativas se inscriben los nombres de "quienes con sus vidas han iluminado el camino a la libertad", de modo tal que, la casa es actualmente un sitio de tipo P1, máxime considerando que una de las inscripciones del aludido monumento expresa que la iniciativa está inspirada “en un afán de mantener viva la memoria histórica”.

Desde la perspectiva de análisis que propone este artículo, el intento de los autores de los crímenes políticos no fue de conmemoración, llegó a serlo por casualidad, o sea que la casa es de tipo P2, mientras que el monumento y las placas de homenaje son de tipo P1, en tanto que la casa llegó a transformarse en un edifico de conmemoración en consecuencia final. La denominación de la casa señala su historia dentro un proceso parecido al del indio desconocido, lo que demuestra una transformación de un tipo de patrimonio al otro.

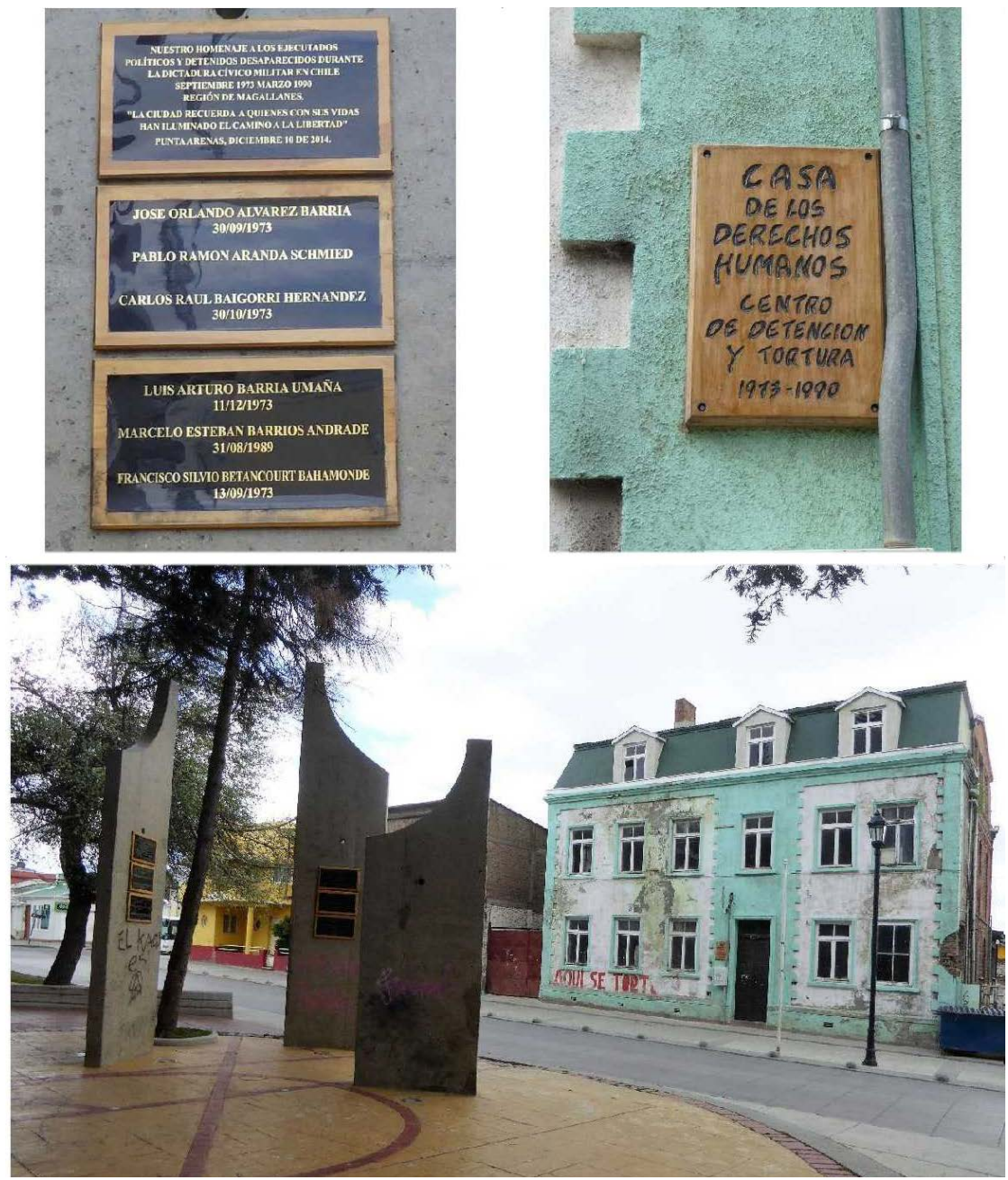

Fig. 3. Monumento de homenaje a los ejecutados políticos y detenidos desaparecidos, y la Casa de los Derechos Humanos, Punta Arenas, Chile. (Fotos Iain Davidson).

15 Consejo de Monumentos Nacionales de Chile (2 de mayo de 2016) Casa de los Derechos Humanos de Punta Arenas es Monumento Nacional. URL: http://monumentos.cl/consejo/606/w3-article-58938.html 
El hecho de que al interior de una cultura exista una práctica de creación de lugares patrimoniales de tipo P1, fomenta la posibilidad de defender este tipo de sitios patrimoniales de tipo P2 y transformarlos en tipo P1. Es en este proceso donde se ven más claramente las posibilidades de una lucha política. Por un lado, están los defensores de la preservación del patrimonio, y por el otro, están los intereses disímiles en relación a la memoria histórica, o que presionan por los usos alternativos de la tierra. Por esta razón, se hizo necesario aprobar una legislación que estuviera orientada a establecer las pautas para resolver tales disputas.

\section{Conservación y protección bajo la ley}

En los países existen legislaciones que apunta a proteger los sitios patrimoniales, y por ello, en cada lugar que cuenta con estas políticas de protección patrimonial, se tendrá el problema de la gestión del conflicto entre los intereses de los defensores del patrimonio y de las otras partes interesadas. Sin embargo, paradójicamente, parece probable que en toda forma de legislación subyace la siguiente premisa: que éstas son escritas para permitir la destrucción del patrimonio, en los casos que se cumplen ciertas condiciones.

Un ejemplo de leyes para la "protección" del patrimonio cultural es la ley de Western Australia (Western Australian Aboriginal Heritage Act 1972 -Ley del Patrimonio Aborigen de Australia Occidental- WAAHA). La sección 10 de esta ley dice lo siguiente:

"El Ministro tiene el deber de velar por que, en la medida de lo razonablemente posible, todos los sitios de Australia occidental que tengan un significado sagrado, ritual o ceremonial tradicional o actual para las personas de ascendencia aborigen, se registren en nombre de la comunidad y se evalúe su importancia relativa, para que los recursos disponibles de vez en cuando, para la preservación y protección de esos lugares, puedan coordinarse y hacerse efectivos" (Aboriginal Heritage Act, 1972, p. 6) ${ }^{16}$.

Analizando la cita precedente, se puede concluir que: a) Se desea registrar los sitios de importancia para las personas de ascendencia aborigen; b) Cualquier otra medida de evaluar la importancia, preservar o proteger los sitios depende de la disponibilidad de recursos. En tal sentido, nada dice de la existencia de una necesidad de conseguir recursos, prerrogativa que recae en la figura del Ministro, y que tal como se encuentra planteado en esta ley, es la causa/origen de un claro conflicto de interés a la hora de evaluar/optar entre la protección patrimonial de un sitio determinado y/o favorecer una propuesta de desarrollo económico. Bajo este marco legal, el Ministro siempre tendrá la posibilidad de aducir la no existencia de recursos disponibles para la protección patrimonial. En base al ejemplo presentado, parece probable que existan modalidades parecidas de evitar la fuerza de la legislación en todos los países.

16 Aboriginal Heritage Act 1972, No 053 (Ley del patrimonio aborigen de 1972 de Australia occidental). URL: https:// www.slp.wa.gov.au/legislation/statutes.nsf/yrbyyr_1972.html 
Lo importante para la protección de cualquier tipo de patrimonio, es que la gente consumidora del patrimonio entienda algo sobre su importancia. Freeman Tilden (1957) dijo hace 60 años que la gente sólo conservará lo que disfruta, y la gente sólo disfruta lo que puede entender. Hoy está bien desarrollada la ciencia de interpretación de sitios patrimoniales (por ejemplo, ver Jiménez, 2015), destacándose la necesidad de un relato central -el mensaje del patrimonio- cuyo requisito fundamental es que debe ser conciso, muy en la línea -por ejemplo- de la filosofía de la red social Twitter. En función de lo anterior, la idea central de lo que se ha venido desarrollando, es que existen varios públicos con intereses en cualquier sitio de patrimonio. Cada uno puede tener un mensaje distinto, y además, el mensaje puede cambiar durante la exposición del fenómeno patrimonial.

Verbigracia, damos cuenta de la importancia de interpretación del patrimonio cultural y material a través del caso del arte rupestre de la Península Burrup de Western Australia (Davidson et al., 2014). El sitio comprende una península y archipiélago de alrededor de 100 km2 donde se encuentran centenares de miles de bloques con petroglifos (Mulvaney, 2013), algunos de ellos probablemente de mucha antigüedad (Mulvaney, 2009). Durante los años 1970 y 80 se construyó una fábrica de gas natural licuado (GNL), incluyendo la fábrica y un puerto, además de otro puerto de transporte de mineral de hierro. El resultado de estos trabajos, antes y después de la aprobación de la ley de protección del patrimonio cultural (WAAHA) de 1972, tuvo como resultado la destrucción de gran cantidad de los bloques incluyendo el arte rupestre.

Durante la construcción de una segunda fábrica de GNL a principios de este siglo hubo una campaña de oposición pública al desarrollo de varias iniciativas, incluyendo la nominación en 2007 de muchas partes de la península al Registro Nacional de Patrimonio, más una campaña, todavía sin éxito, de inscribirlo en la Lista del Patrimonio Mundial de UNESCO. Gran parte de la publicidad relacionada con este arte rupestre, estuvo centrada sobre la base de la asociación de atributos negativos a las empresas ligadas a proyectos de desarrollo económico, y en un porcentaje muy inferior, el mensaje apuntó a destacar los beneficios del patrimonio. A pesar de todo esto, los petroglifos quedaron casi totalmente sin interpretación al público (Fig. 4$)^{17}$.

En una zona donde pasan más de doscientos mil turistas al año -los cuales dejan más de dos millones de noches de alojamiento en la zona18- la falta de interpretación y de posibilidades de informar al público sobre el patrimonio de la región, ha sido un gran problema al momento de contrastar la importancia de la industria y la del patrimonio. El resultado fue que, a pesar de la campaña de publicidad, estas miles de personas no tenían posibilidad ni de disfrutar de

17 Hay posibilidades de que esto cambie. Por ejemplo, el Reporte Turístico de Karratha (2014), fue desarrollado como un documento de apoyo para informar al grupo de asesores turísticos de esta ciudad, situada en Australia Occidental. URL: http://www.pilbararesearchonline.com.au/wp-content/uploads/2015/02/City-of-KarrathaTourism-Report-2014.pdf

18 Informe de visitantes alojados por noche, temporada 2014/2015, ciudad de Karratah, localizada al sur-este de la península Burrup, Australia, y cercana a los sitios de arte rupestre. URL: http://www.tourism.wa.gov.au/ Publications\%20Library/Research\%20and\%20reports/Karratha\%202015.pdf 
los petroglifos, ni de entenderlos. Fue muy difícil, pues, que el público apoyase la conservación del patrimonio. Se nota aquí que la antigüedad de los petroglifos no tiene importancia para el grupo con más interés en el patrimonio del arte: la gente Aborigen. Sin embargo, sí que tiene importancia para los forasteros de este patrimonio: la gente de la sociedad colonizadora.

En este caso las personas aborígenes fueron los productoras del patrimonio (P1), en tanto que los consumidores (P2), podrían ser los miles de turistas que pasan por la zona. Pero el principal obstáculo, está dado por la relación de poder entre los productores y la gente de poder e influencia dentro la sociedad de los colonos (settler society), quienes generalmente no tienen origen aborigen. Dada la fuerza de los intereses del gobierno estatal y local, además del empresarial, fue muy difícil influir en el proceso, al carecer de un grupo de consumidores informados con ganas de entender el patrimonio y de disfrutar de ello.

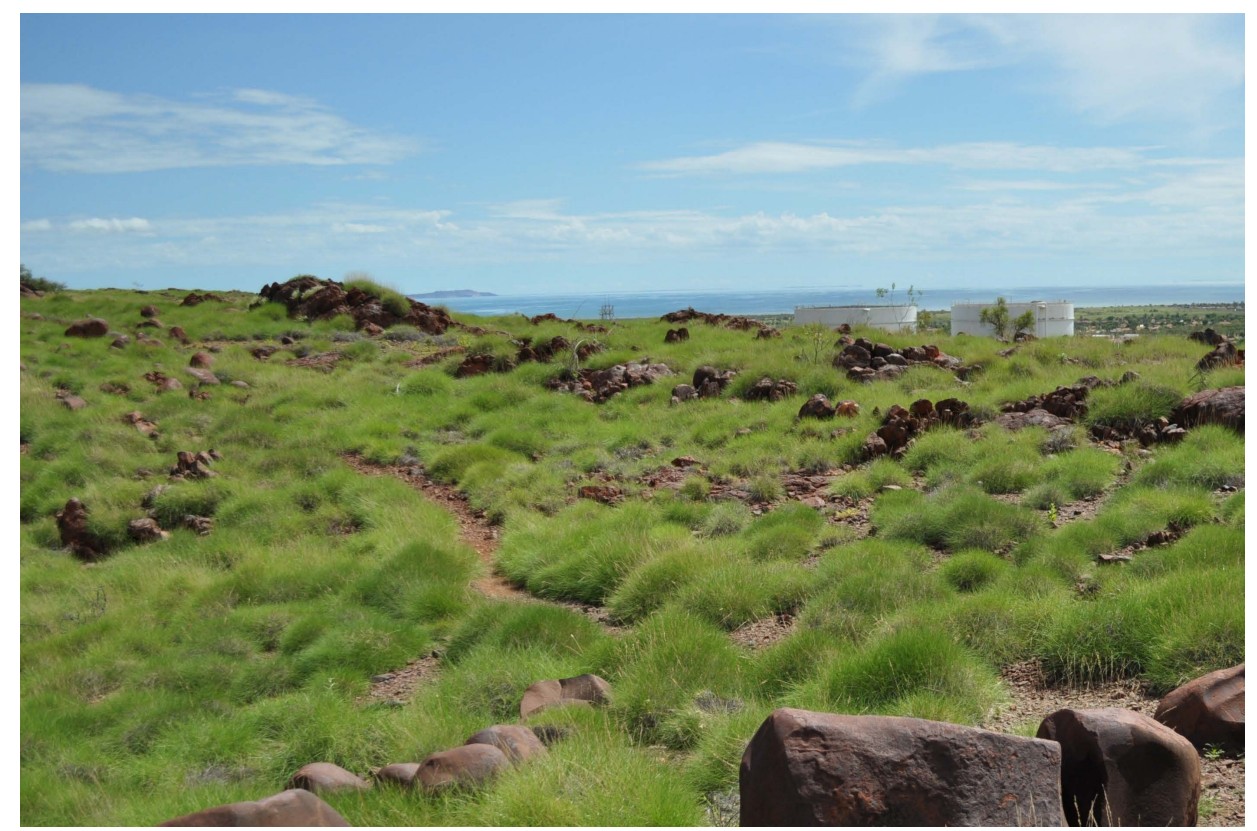

Fig. 4. Grupo de bloques cerca de Karratha, Western Australia, incluyendo algunos marcados por petroglifos en medio camino del sendero patrimonial, sin intento de interpretación.

(Foto Iain Davidson, marzo 2011).

\section{CONCLUSIONES}

El caso presentado en el párrafo anterior, denota que uno de los elementos claves a la hora de abogar por el cuidado del patrimonio, es hacer que los consumidores del patrimonio tengan la información para entender lo que se defiende.

Aquello queda de manifiesto en los dos sitios patrimoniales analizados en este artículo, dado que ni el memorial del "Indio desconocido" ni la "Casa de los Derechos Humanos" tienen señalización con interpretaciones que apunten a explicar el hecho de por qué se conservan.

Como se veía con el primer caso, el significado patrimonial de un lugar puede cambiar 
con el tiempo, lo que queda ejemplificado en las polémicas acciones que recientemente se han suscitado relacionadas con la acción de quitar manifestaciones materiales del patrimonio (memoriales, como el de Anzac Cove en Turquía, o una estatua, como la del juez Waldo Seguel, en la ciudad de Punta Arenas) que tengan una historia desafortunada. Para algunos, esto significa la destrucción de la historia, en tanto que para otros, no es tanto destruirla, sino más bien proporcionar una interpretacion alternativa de lo que habria sucedido.

En realidad, las estatuas erigidas en lugares públicos pueden tener diferentes significados para diferentes personas. Los elementos interpretativos pueden evitar malentendidos, y pueden cambiarse a medida que las personas acuden a visitar un patrimonio del tipo P1 bajo una luz diferente. En consecuencia, los elementos interpretativos que explican por qué un lugar tiene significado para el patrimonio, se convierten en sí mismo, en parte de la herencia de un lugar. El significado del patrimonio, siendo el resultado de actos políticos, merece interpretación y re-interpretación según la política y el contexto del momento.

\section{REFERENCIAS}

Bennett, T. (2005). Culture. En T.Bennett, L. Grossberg \& M. Morris (Eds.), New keywords. A revised vocabulary of culture and society (pp. 63-69). Oxford: Blackwell Publishing.

Davidson, I. (2008). El futuro del patrimonio histórico: ¿Por qué debemos ocuparnos de la herencia cultural? En M. García, M. A. Jiménez, V. Thiébaut (Eds.) Patrimonio y paisajes culturales. México: El Colegio de Michoacán, A.C.

Davidson, I. (2011). Somos todos de fuera - We are all from somewhere else. Thoughts on the responsibilities of archaeologists. En Bicho, N. (Ed.), História, Teoria e Método da Arqueologia. Actas do IV Congresso de Arqueologia Peninsular (pp. 245-250). Faro, Portugal: Universidade do Algarve.

Davidson, I. (2016). Stone tools: evidence of something in between culture and cumulative culture? En M. Haidle, N. Conard \& M. Bolus (Eds.), The Nature of Culture (pp. 99-120). Vertebrate Paleobiology and Paleoanthropology. Holanda: Springer.

Davidson, I., Douglas, T., \& Hicks, W. (2014). Burrup Peninsula. En C. Smith (Ed.), Encyclopedia of Global Archaeology. New York: Springer.

González, P. (2004). Protección jurídica del patrimonio cultural: logros y encrucijadas del patrimonio antoropoarqueológici Chileno. Chungara, 36, 509-522.

Harrison, R. (2010). What is heritage. Understanding the politics of heritage. Manchester: Manchester University Press.

Hartley, L. P. (1953). The Go-Between. Harmondsworth. UK: Penguin Books.

$\mathrm{Hu}, \mathrm{D}$. (2017). The revolutionary power of Andean folk tales. Sapiens. URL: https://www. sapiens.org/archaeology/andean-folk-tales-revolutionary-power/. Fecha de consulta 4 de Julio de 2017.

Jiménez, M. A. (2015). Una metodología para la creación de guiones de divulgación del 
patrimonio arqueológico. Intervención, 6(12), 13-24.

Kuper, A. (1999). Culture. The anthropologists' account. Cambridge, MA, USA: Harvard University Press.

Mulvaney, K. J. (2009). Dating the Dreaming: extinct fauna in the petroglyphs of the Pilbara region, Western Australia. Archaeology in Oceania, 44(1), 40-48.

Mulvaney, K. J. (2013). Iconic imagery: Pleistocene rock art development across northern Australia. Quaternary International, 285, 99-110.

Plath, O. (1993). L’Animita: Hagiografía Folklórica. Santiago: Editorial Pluma y Pincel.

Rivera, M. (2012). El Tráfico Internacional de Bienes Arqueológicos. El Caso de Chile en el Contexto Latinoamericano. En M. C. Mineiro \& A. Soberón, A. (Eds.), El Patrimonio Cultural de América, Tomo 1 Investigación y Educación Patrimonial (pp. 151-177) México: Instituto Panamericano de Geografía e Historia.

Risopatrón, L. (1924). Diccionario Jeográfico de Chile. Santiago de Chile: Imprenta Universitaria. Subercaseaux, B. (2005). Chile, o, una loca Geografía. Santiago de Chile: Editorial Universitaria. Tilden, F. (1957). Interpreting our heritage. Chapel Hill: University of North Carolina Press Tylor, E. B. (1871). Primitive culture. Researches into the development of mythology, philosophy, religion, language, art, and custom. London: John Murray.

Zorich, Z. (2016). Tallying the losses in Palmyra. Science, 352(6282), 130-131. 